\title{
Influence of membrane galactolipids and surface pressure on plastoquinone behaviour
}

\author{
Javier Hoyo ${ }^{a}$, Ester Guaus ${ }^{a}$, Juan Torrent-Burgués ${ }^{a^{*}}$ \\ ${ }^{a}$ Universitat Politècnica de Catalunya, Group of molecular and industrial biotechnology, \\ Dpt. Chemical Engineering, 08222 Terrassa (Barcelona), Spain \\ *Corresponding autor: juan.torrent@upc.edu. Colom 1, 08222 Terrassa (Barcelona), Spain, \\ Tlf: +34 937398043.
}

\begin{abstract}
In this work biomimetic monolayers of a MGDG, monogalactosyldiacylglycerol, and DGDG, digalactosyldiacylglycerol mixture (MD), in a ratio close to that of the thylakoid membranes of oxygenic photosynthetic organisms, have been prepared. The lipid mixture incorporates plastoquinone-9 (PQ), that is the electron and proton shuttle of the photosynthetic reaction centres. The MD:PQ mixtures have been firstly studied using surface pressure-area isotherms. Langmuir-Blodgett (LB) films of those mixtures have been transferred onto a substrate forming a monolayer that mimics one of the bilayer side of the thylakoid membranes. These monolayers have been characterized topographically and electrochemically. The results show the influence of PQ in the MD matrix and its partial expulsion when increasing the surface pressure, obtaining two main PQ positions in the MD matrix. The calculated apparent electron transfer rate constants indicate a different kinetic control for the reduction and the oxidation of the $\mathrm{PQ} / \mathrm{PQH}_{2}$ couple, being $\mathrm{k}_{\text {Rapp }}(\mathrm{I})=$ $0.7 \cdot 10^{-6} \mathrm{~s}^{-1}, \quad \mathrm{k}_{\text {Rapp }}(\mathrm{II})=2.2 \cdot 10^{-9} \mathrm{~s}^{-1}, \mathrm{k}_{\text {Oapp }}(\mathrm{I})=7.4 \cdot 10^{-4} \mathrm{~s}^{-1}$ and $\mathrm{k}_{\text {Oapp }}(\mathrm{II})=5.2 \cdot 10^{-5} \mathrm{~s}^{-1}$, respectively. The comparison of the different galactolipid:PQ systems that our group have studied is also presented, concluding that the PQ position in the galactolipid matrix can be tuned according to several controlled variables.
\end{abstract}

Keywords

Biomimetic membrane; monogalactosyldiacylglycerol; digalactosyldiacylglycerol; plastoquinone; Langmuir-Blodgett film; electron transfer.

\section{Highlights}

Biomimetic films of MGDG-DGDG (MD) incorporating plastoquinone (PQ) have been built.

PQ presents two main positions in the MD matrix: diving and swimming.

PQ positions can be tuned by several controlled variables.

The behaviour of the mixed MGDG-DGDG films is in between those of the individual components. 


\section{Introduction}

Artificial lipid bilayers have been extensively studied as membrane models to mimic natural membranes. They have shown their relevance in a broad range of chemical, biological and technological applications, one of them being the development of artificial photoelectric devices [1-5]. Photosynthesis takes place in the thylakoid membrane of oxygenic photosynthetic organisms which is constituted by a lipid matrix that maintains the fluidity of the membrane, allows an electrochemical potential difference across this membrane and harbours the protein complexes of the photosynthetic machinery [6]. In cyanobacterias, thylakoid membranes develop infoldings from the plasma membrane which in higher plants are located in the chloroplasts. Moreover, this lipid matrix embeds plastoquinone-9 (PQ) (Schematic 1A), which is the electron and proton shuttle between photosystem II and cytochrome. On the other hand, the lipid content of this thylakoid matrix depends on the species and the external conditions. However, it can be agreed that the thylakoid membrane of a typical oxygenic photosynthetic organism is composed of the following lipids: monogalactosyldiacylglycerol $(\mathrm{MGDG}) \approx 50 \%$ (Schematic $1 \mathrm{C}$ ), digalactosyldiacylglycerol (DGDG) $\approx 30 \%$ (Schematic $1 \mathrm{D})$, and small amounts of other lipids, phosphatidylglycerol (PG) and sulfoquinovosyldiacylglycerol (SQDG) [6,7]. Crystal structures of the photosystem II obtained with resolution between 3.8-2.9 $\AA$ reveal that its lipid composition reflects that of the thylakoid membrane but that the distribution is asymmetric [8]. The head groups of negatively charged PG and SQDG are exclusively located on the cytoplasmic (stroma) side, those of the uncharged DGDG on the luminal side and those of MGDG on both sides.
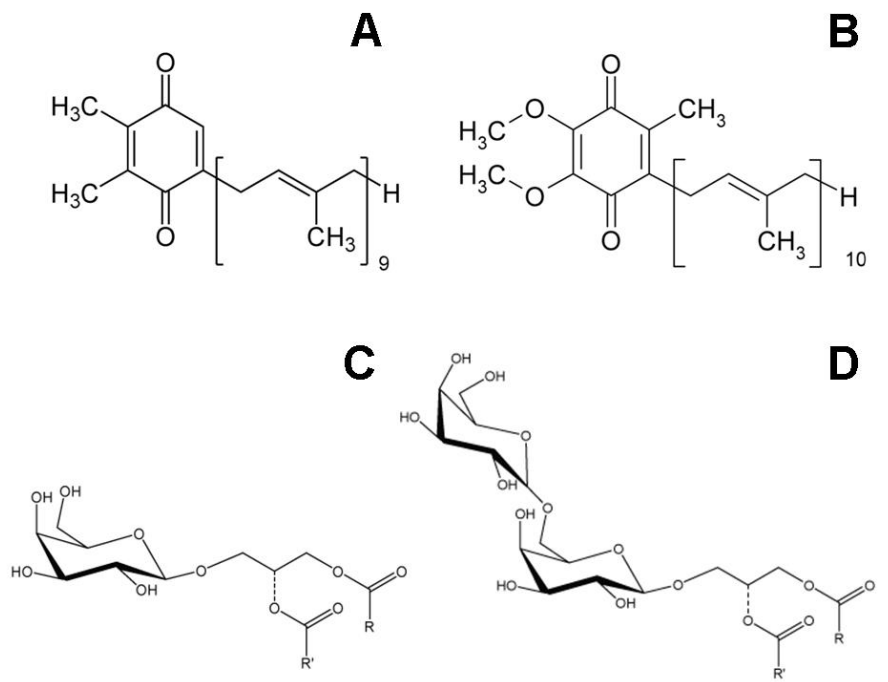

Schematic 1. Scheme of a molecule of (A) PQ-9, (B) UQ-10, (C) MGDG and (D) DGDG.

In previous work, our group has prepared biomimetic membranes composed of one kind of lipid (MGDG, DGDG or DPPC), mixed with PQ or ubiquinone-10 (UQ) (Schematic 1B) that is similar in size and shape to PQ [9-15]. Several lipid:quinone ratios have been studied and we have determined the position in the lipid matrix of the PQ or UQ. The positions obtained are in line with the diving and swimming positions proposed by the Söderhäl and Laaksonen computer simulations [16]. 
In order to prepare reliable membranes that can mimic natural photosynthesis, the lipid content and the chemical nature of this membrane should be close to natural ones $[6,8]$.

With this aim, in this work, we have prepared biomimetic monolayers of MGDG-DGDG at a ratio of 2:1, that we designate as MD in the work, and MD and PQ (MD:PQ) systems at a ratio of 5:1. The selection of the 5:1 ratio is based on our experience [9-12], and is the ratio closest to the biological one and shows the best-defined characteristics, especially when using cyclic voltammetry. The MGDG:DGDG ratio in the MD mixture is close to the natural one of thylakoid membranes and, in addition, it represents $\approx 80 \%$ of the thylakoid membrane lipid composition. The biomimetic monolayers are prepared using Langmuir and Langmuir-Blodgett (LB) techniques and are studied using surface pressure - Area $(\pi-A)$ isotherms and their data are processed to discern their physical states and mixing behaviour. These monolayers, once transferred to a mica substrate at several surface pressures (including the lateral surface pressure $\approx 33 \mathrm{mN} \cdot \mathrm{m}^{-1}$ of natural membranes)[17], have been topographically studied using Atomic Force Microscopy (AFM) to observe the influence of PQ in the MD matrix. Finally, we have used the cyclic voltammetry technique for studying the electrochemical behaviour of the monolayers once transferred to indium-tin oxide (ITO), which has good optical and electrical properties, so making ITO a candidate for studying artificial photosynthesis and other energy producing devices [18].

\section{Materials and methods}

\subsection{Materials}

PQ was provided by ASM Research Chemicals. MGDG and DGDG, both with acyl = stearoyl (18:0), were purchased from Matreya (USA). $\mathrm{KH}_{2} \mathrm{PO}_{4}, \mathrm{KCl}$ and chloroform of analytical grade from Sigma-Aldrich were used in solution preparation. Water was ultrapure MilliQ® $(18.2 \mathrm{M} \Omega \cdot \mathrm{cm})$. Mica sheets were purchased from TED PELLA Inc (CA) and ITO-deposited on glass slides was purchased to SOLEMS (France).

\subsection{Methods}

\subsubsection{Monolayer formation}

Langmuir and Langmuir-Blodgett monolayer formation were carried out in a trough model 1232D1D2 (Nima Technology, Cambridge, UK) equipped with two movable barriers. The surface pressure was measured using Whatman filter paper grade 1 held by a Wilhelmy balance connected to a microelectronic system registering the surface pressure.

The subphase used in these experiments was MilliQ® quality water. Previous to subphase addition, the trough was cleaned twice with chloroform and once with MilliQ ${ }^{\circledR}$ quality water. Residual impurities were cleaned from the airlliquid interface by surface suctioning. The good baseline in the $\pi-A$ isotherms confirms the interface cleanliness. Solutions of MD (MD = MGDG:DGDG in molar ratio 2:1), PQ and MD:PQ 5:1 were prepared using chloroform and spread at the air|liquid interface using a high precision Hamilton microsyringe. LB monolayers were transferred to mica surface at defined surface pressure values. Barrier closing rates were fixed at $50 \mathrm{~cm}^{2} \cdot \min ^{-1}\left(8.6 \AA^{2} \cdot \mathrm{molecule}^{-1} \cdot \mathrm{min}^{-1}\right)$ for isotherm registration and at $25 \mathrm{~cm}^{2} \cdot \mathrm{min}^{-1}\left(4.3 \AA^{2} \cdot\right.$ molecule $\left.^{-1} \cdot \mathrm{min}^{-1}\right)$ for LB film transfer. No noticeable influence of these compression rates was observed on the isotherm shape. Isotherm recording was carried out by adding the solution to the subphase and waiting 15 
minutes for perfect spreading and solvent evaporation. LB film transfer was conducted by dipping the freshly cleaved mica or freshly cleaned ITO through the air|liquid interface on the subphase before adding the solution, and waiting five minutes after pressure setpoint was achieved. Transfer speed was set at $5 \mathrm{~mm} \cdot \mathrm{min}^{-1}$ linear velocity and the transfer ratios obtained were close to 1 . Experiments were conducted at $21 \pm 1^{\circ} \mathrm{C}$ and repeated for reproducibility control.

\subsubsection{AFM characterization}

The AFM topographic images of LB films were acquired in air tapping mode using a Multimode AFM controlled by Nanoscope IV electronics (Veeco, Santa Barbara, CA) under ambient conditions. Triangular AFM probes with silicon nitride cantilevers and silicon tips were used (SNL-10, Bruker), which have a nominal spring constant $\approx 0.35 \mathrm{~N} \cdot \mathrm{m}^{-}$ 1. Images were acquired at a line frequency of $1.5 \mathrm{~Hz}$ and at minimum vertical force to reduce sample damage. AFM images were obtained from at least two different samples, prepared on different days, and by scanning several macroscopically separated areas on each sample.

\subsubsection{Electrochemical characterization}

Voltammetric measurements were performed in a conventional three-electrode cell using an Autolab Potentiostat-Galvanostat PGSTAT-12 (Ecochemie, NL). Working electrodes were freshly-cleaned ITO slides $(10 \mathrm{~mm} \times 25 \mathrm{~mm})$ cleaned once with ethanol and three times with MilliQ ${ }^{\circledR}$ grade water. The counter electrode was a platinum wire in spiral geometry and the reference electrode was an $\mathrm{Ag}|\mathrm{AgCl}| 3 \mathrm{M} \mathrm{KCl}$ microelectrode (DRIREF-2SH, World Precision Instruments). This reference electrode was mounted in a Luggin capillary containing $\mathrm{KCl}$ solution at the same cell concentration. All reported potentials were referred to this electrode. The electrochemical cell contained $0.150 \mathrm{M} \mathrm{KCl}$ as supporting electrolyte at $\mathrm{pH} 7.4$ adjusted with the $\mathrm{KH}_{2} \mathrm{PO}_{4} / \mathrm{K}_{2} \mathrm{HPO}_{4}$ buffer solution. All solutions were freshly prepared with MilliQ ${ }^{\circledR}$ grade water de-aerated with a flow of Ar gas for 15 min prior to the cyclic voltammetry experiments, which were conducted at $21 \pm 1^{\circ} \mathrm{C}$. Voltammetric experiments were carried out by scanning towards cathodic potentials in a homemade glass cell with a reaction area of $33 \mathrm{~mm}^{2}$.

\section{Results and discussion}

\section{$3.1 \pi$-A isotherms, physical states and mixing behavior}

The $\pi$-A isotherms of MD, PQ and their mixtures at biologically relevant ratios referred to the MD area per molecule are presented in Fig. 1. The inset of Fig. 1 represents the inverse of the compressibility modulus $\left(C_{s}^{-1}\right)$ curves corresponding to the described $\pi$-A isotherms, and they are calculated according to Eq. (1).

$$
C_{s}^{-1}=-A\left(\frac{d \pi}{d A}\right)_{T}
$$

It can be observed in Fig. 1 that the MD:PQ mixture presents a marked effect due to the PQ presence in the MD matrix. The MD:PQ isotherm is displaced to higher areas than the MD 
isotherm, at the beginning of the compression, and it shows a kink point around $2 \mathrm{mN} \cdot \mathrm{m}^{-1}$. In addition, the mixture never meets the pure MD $\pi$-A isotherm which indicates the presence of PQ in the MD matrix even at high surface pressures. According to the $C_{s}^{-1}$ values presented by Vitovic et al. [19] and the characteristics of this system, the kink point present at $\pi \approx 3 \mathrm{mN} \cdot \mathrm{m}^{-1}$ indicates the phase change from liquid expanded (LE) to liquid condensed (LC), which implies the main PQ expulsion from the lipid matrix. It is also interesting to observe that the MD:PQ system presents lower $C_{s}^{-1}$ values than the MD, as was expected.

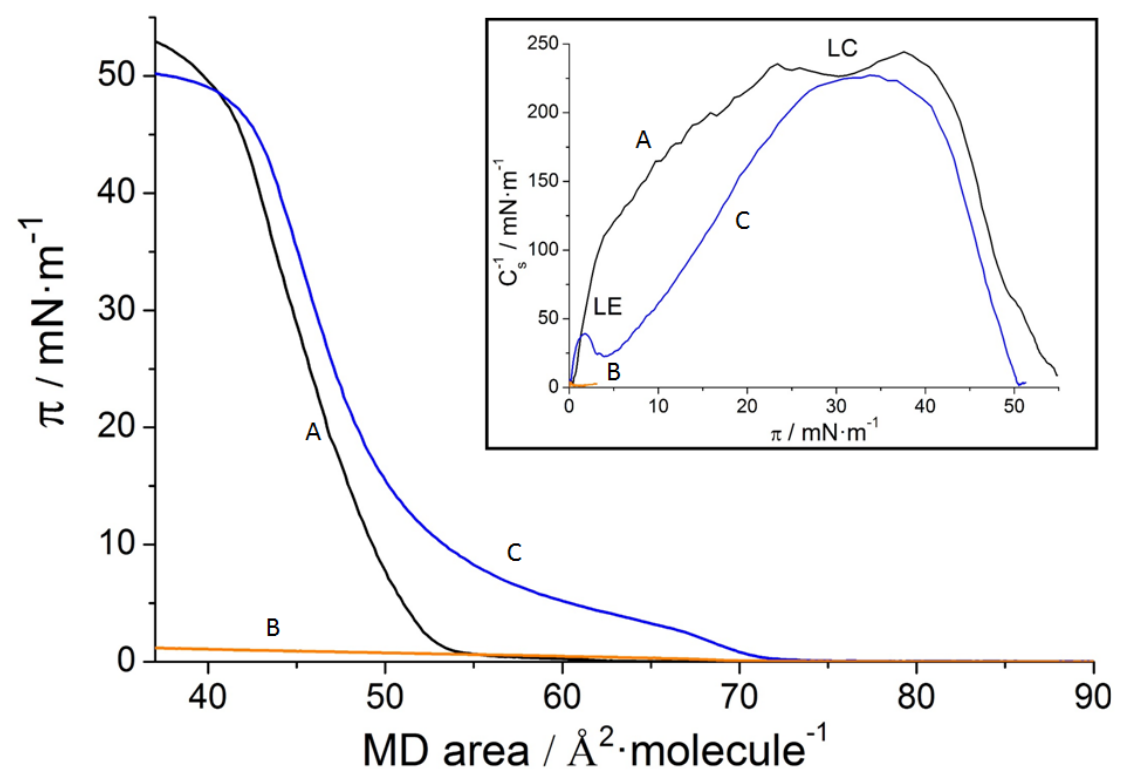

Figure 1. $\pi$-A isotherms for: (A) MD (MGDG:DGDG 2:1), (B) PQ and (C) MD:PQ mixture, at $21 \pm$ $1{ }^{\circ} \mathrm{C}$ on water subphase. Inset represents the inverse of the compressibility modulus $\left(C_{s}^{-1}\right)$ curves corresponding to the described $\pi$-A isotherms.

By comparing the $C_{s}^{-1}$ curves of MD:PQ with those of MGDG:PQ [9] and DGDG:PQ [10] (Fig. S1 in Supplementary material), it can be observed that all of them present an initial LE zone that changes to LC after the kink point. The slope of the zone after the kink point for the DGDG:PQ and MD:PQ is similar but it differs from that of the MGDG:PQ. However, the kink point position for the MGDG:PQ and MD:PQ is similar and different from that corresponding to the DGDG:PQ system. The explanation for these observations is the more fluid physical state of pure DGDG compared with MGDG. Moreover, the presence of PQ affects the compactness of MGDG to a larger extent than it affects that of DGDG, which explains the similar position of the kink point between MGDG:PQ and MD:PQ.

The thermodynamic study of the system can be done with Eqs (2)-(5), and it is only applicable to low surface pressures.

$$
\begin{aligned}
& A^{E}=A_{12}-\left(x_{1} A_{1}+x_{2} A_{2}\right) \\
& G^{E}=N_{A} \int_{0}^{\pi} A^{E} d \pi \\
& \Delta \mathrm{G}_{\mathrm{mix}}=\Delta \mathrm{G}_{\mathrm{id}}+\mathrm{G}^{\mathrm{E}} \\
\Delta \mathrm{G}_{\mathrm{id}}= & \mathrm{RT}\left(\mathrm{x}_{1} \ln \mathrm{x}_{1}+\mathrm{x}_{2} \ln \mathrm{x}_{2}\right)
\end{aligned}
$$


where $A^{E}$ is the excess area, $A_{12}$ the mean area per molecule for the mixture, $A_{1}$ and $A_{2}$ the area per molecule and $\mathrm{x}_{1}$ and $\mathrm{x}_{2}$ the molar fraction, for MD and $\mathrm{PQ}$, respectively, while $\mathrm{N}_{\mathrm{A}}$ is Avogadro's number, $\mathrm{R}$ the gas constant and $\mathrm{T}$ the absolute temperature.

Table 1. Values of excess area $\left(A^{\mathrm{E}}\right)$, excess free energy $\left(\mathrm{G}^{\mathrm{E}}\right)$ and free energy of mixing $\left(\triangle \mathrm{G}_{\text {mix }}\right)$ for MD:PQ mixtures, and for MGDG:PQ and DGDG:PQ mixtures.

\begin{tabular}{|llccc|}
\hline \multirow{4}{*}{ MD:PQ } & $\pi / \mathrm{mN} \cdot \mathrm{m}^{-1}$ & 1 & 2 & 3 \\
& $\mathrm{~A}^{\mathrm{E}} / \AA^{2} \cdot \mathrm{molecul}^{-1}$ & 58 & 57 & 55 \\
& $\mathrm{G}^{\mathrm{E}} / \mathrm{J} \cdot \mathrm{mol}^{-1}$ & 32 & 99 & 158 \\
& $\Delta \mathrm{G}_{\text {mix }} / \mathrm{J} \cdot \mathrm{mol}^{-1}$ & -1100 & -1080 & -1010 \\
MGDG:PQ & $\Delta \mathrm{G}_{\text {mix }} / \mathrm{J} \cdot \mathrm{mol}^{-1}$ & -1050 & -900 & \\
DGDG:PQ & $\Delta \mathrm{G}_{\text {mix }} / \mathrm{J} \cdot \mathrm{mol}^{-1}$ & -1070 & & -870 \\
\hline
\end{tabular}

The values obtained for $\mathrm{G}^{\mathrm{E}}$ (Table 1) indicate that MD and PQ form non-ideal mixtures with a positive deviation at $\pi \leq 3 \mathrm{mN} \cdot \mathrm{m}^{-1}$ (surface pressure of the main PQ expulsion). This observation indicating that, at these surface pressures, the interactions between the two components are weaker than the interactions between pure components [20]. On the other hand, the negative values observed for $\Delta \mathrm{G}_{\text {mix }}$ at $\pi \leq 3 \mathrm{mN} \cdot \mathrm{m}^{-1}$, even though these values are only slightly negative, indicate that the mixed monolayers of MD:PQ are more stable than pure components [20].

The thermodynamic studies performed for the different galactolipid:PQ mixtures show that they form non-ideal mixtures with positive deviation at low surface pressures (before that corresponding to the PQ expulsion). In addition, the negative values observed at low surface pressures for $\Delta \mathrm{G}_{\text {mix }}$ (Table 1) indicate that the mixed monolayers of galactolipid:PQ are more stable than pure components, although the low $\Delta \mathrm{G}_{\mathrm{mix}}$ values confirm the low stability of the mixture. Comparing the $\Delta \mathrm{G}_{\text {mix }}$ values for all the systems (Table 1) it is seen that the MD:PQ system, which is present in natural thylakoid membranes, is slightly more stable than the individual MGDG:PQ or DGDG:PQ systems.

\subsection{AFM}

Fig. 2 presents the AFM topographic images corresponding to MD (Images A-C) and MD:PQ (Images D-F) transferred at several surface pressures on mica. 

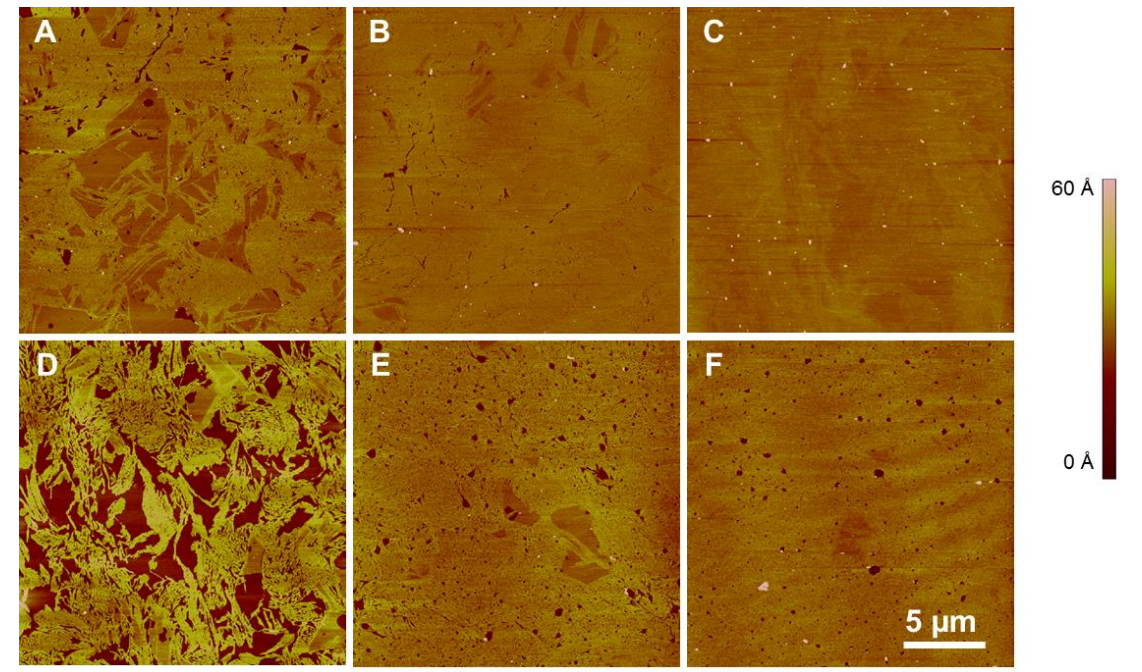

Figure 2. AFM images $(20 \mu \mathrm{m} \times 20 \mu \mathrm{m})$ for LB films transferred on mica at $21^{\circ} \mathrm{C}$. MD at (A) $\pi=1$ $\mathrm{mN} \cdot \mathrm{m}^{-1}$, (B) $\pi=15 \mathrm{mN} \cdot \mathrm{m}^{-1}$, (C) $\pi=33 \mathrm{mN} \cdot \mathrm{m}^{-1}$. MD:PQ at (D) $\pi=1 \mathrm{mN} \cdot \mathrm{m}^{-1}$, (E) $\pi=15 \mathrm{mN} \cdot \mathrm{m}^{-1}$, (F) $\pi=33 \mathrm{mN} \cdot \mathrm{m}^{-1}$.

The images A-C of Fig. 2 present different tonalities of brown. All of these tonalities correspond to zones with different heights of the MD monolayer. The images D-F of Fig. 2 also show three different tonalities of brown (light, medium and dark) and all of them correspond to the MD:PQ monolayer, each tonality being correlated with a different order of the molecules. The compression of the MD:PQ system leads to greater compactness of the more ordered zones till $\pi=33 \mathrm{mN} \cdot \mathrm{m}^{-1}$ where practically the entire monolayer is compact, with only small rounded zones with the molecules in a less ordered state.

Each brown tonality indicates a different tilt order of the molecules that depends on the surface pressure and the interactions established between molecules and between the molecules with the substrate. In order to discern each physical state, we have measured the relative height between light and medium brown zones referred to the dark zones. The MD or MD:PQ systems do not form pin-hole defects that reach the mica. So, we will assume a height of $6 \pm 2 \AA$ for the dark brown zones referred to the mica surface. The selection of this height value for the dark zones is based on the height measured for the MGDG:PQ 5:1 system [9] and moreover, this height is in accordance with the 3-6 $\AA$ observed in the literature for the LE state of DPPC monolayers [21,22]. The absolute height for the physical states LC1, corresponding to molecules at the beginning of the LC state, and LC2, molecules in the most ordered state of the LC state, are $21 \pm 1$ and $25 \pm 1 \AA$, respectively, for pure MD. On the other hand these values are $22 \pm 1$ and $24 \pm 1 \AA$, respectively, for the MD:PQ 5:1 system. The absolute heights obtained at each surface pressure and considering the $C_{s}^{-1}$ results permit the determination of the physical state corresponding to each tonality at each surface pressure (Table 2).

The MD and MD:PQ mixture monolayers cover the entire mica surface at all the studied surface pressures. The absence of uncovered mica zones permits the determination of the proportion of each physical state. Table 2 presents the percentage of the monolayer in the most compact state, so the proportion of each physical state can be elucidated. It can be observed that with increased surface pressure the MD:PQ system increases the presence of LC zones, achieving at $\pi=15 \mathrm{mN} \cdot \mathrm{m}^{-1}$ a nearly flat increase. This finding correlates with the fact that most of the PQ content has been rejected from the lipid matrix. On the other 
hand, pure MD presents a nearly flat increase of the area covered by the more compact phase when the surface pressure increases. The explanation is the relatively quick transformation of the LE to the LC state, which leads to the entire monolayer being in a highly ordered state at $15 \mathrm{mN} \cdot \mathrm{m}^{-1}$.

Table 2. Physical states of each zone (dark and light brown) and monolayer coverage of the light brown zones on the mica surface corresponding to the MD and MD:PQ systems at several surface pressures obtained from the AFM images.

\begin{tabular}{|ccccccc|}
\hline & \multicolumn{4}{c}{ MD } & \multicolumn{4}{c|}{ MD:PQ 5:1 } \\
$\pi$ & Dark & Light & Coverage & Dark & Light & Coverage \\
$\left(\mathrm{mN} \cdot \mathrm{m}^{-1}\right)$ & & & $\%$ & & & $\%$ \\
1 & LE & LC1 & 96.7 & LE & LC1 & 63.1 \\
6 & LE & LC1 & 98.5 & LE & LC1 & 83.8 \\
15 & LE & LC2 & 99.1 & LE & LC1 & 96 \\
33 & LC1 & LC2 & 99.7 & LE & LC2 & 99.2 \\
\hline
\end{tabular}

From comparing the AFM images of the galactolipid:PQ mixtures (Fig S2 in Supplementary material) it is evident that MGDG:PQ and MD:PQ present similar topographic images and both differ to that corresponding to the DGDG:PQ system, which presents the LC phase in circular domains forming islands. These images and the observations in the $C_{s}^{-1}$ curves (Fig. S1) indicate that the MGDG, as it is the major component, leads the domains shape and the PQ expulsion. However, the fluidity of the mixture is led by the DGDG, which is more fluid than MGDG. The absolute phase heights obtained for the galactolipid:PQ systems and the physical state corresponding to each brown tonality at $\pi=15 \mathrm{mN} \cdot \mathrm{m}^{-1}$ are exposed in Table S1 (in Supplementary material). Despite the fact that all the galactolipid:PQ systems studied present practically the same physical states, the absolute heights of each physical state of the galactolipid:PQ systems present small differences, which are explained by the different galactolipid-PQ interactions that can occur depending on the mixture components. It is also seen that the heights for the MD:PQ mixture are more similar to those of DGDG:PQ than to those of MGDG:PQ, in accordance with the physical states.

\subsection{Electrochemical behavior}

The electrochemical behavior of the ITO-MD|electrolyte, ITO-PQ|electrolyte and ITOMD:PQ|electrolyte systems is studied in this section. In our experiments, three cyclic voltammograms (CVs) are required to obtain the stationary state in the electrochemical response, presenting a good reproducibility from the third scan and at least 15 cycles. 
Fig. 3 presents the $\mathrm{CVs}$ at $10 \mathrm{mV} \cdot \mathrm{s}^{-1}$ of the ITO-MD system transferred at several surface pressures which, in part, are the same as were selected for topographic AFM imaging on mica. The voltammograms indicate that in the potential range between 0.80 and $-0.2 \mathrm{~V}$ the ITO-MD electrode does not show faradaic responses and that the effect of the applied electrical potential on the lipid monolayer is low. At more anodic potentials than $-0.20 \mathrm{~V} \mathrm{a}$ continuous increase of the intensity was obtained, indicating hydrogen evolution. This behaviour was also reported for the ITO-MGDG electrode in which the hydrogen evolution started at potentials more cathodic than $-0.40 \mathrm{~V}$ [12]. The cyclic voltammogram of the ITOMD/electrolyte system has been used to evaluate its $C_{d}$ (Inset of Fig. 3) from the values of the voltammetric charging current [14]. The ITO-MD electrode presents higher $\mathrm{C}_{\mathrm{d}}$ values than bare ITO, increasing from 2 to $4.5 \mu \mathrm{F} \cdot \mathrm{cm}^{-2}$ when scanning from 0.90 to $-0.30 \mathrm{~V}$. $\mathrm{C}_{\mathrm{d}}$ values $\approx 1.8 \mu \mathrm{F} \cdot \mathrm{cm}^{-2}$ have been reported for high quality lipid monolayers [12] so indicating that our monolayer is not completely homogeneous and presents few defects. The fact that the voltamogram presents reproducible behaviour indicates that the lipid layer is permeable to water molecules, and after the third scan, stable water content is achieved in the monolayer.

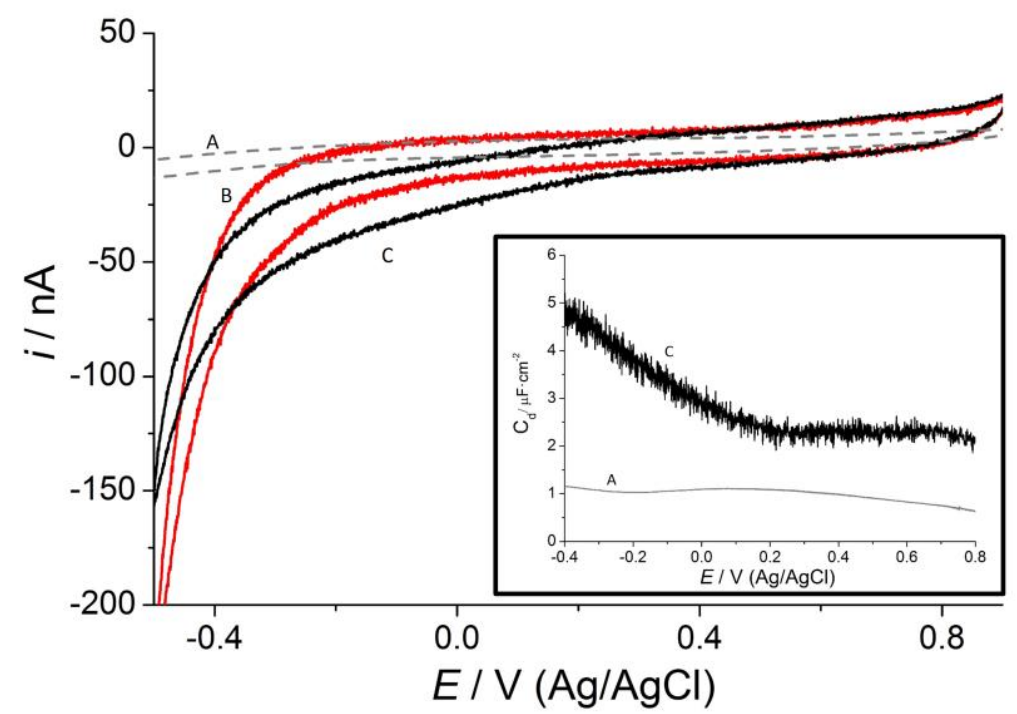

Figure 3. Cyclic voltammograms of: (A) the ITO/electrolyte and (B, C) ITO-MD/electrolyte system at (B) $\pi=1 \mathrm{mN} \cdot \mathrm{m}^{-1}$ and (C) $\pi=33 \mathrm{mN} \cdot \mathrm{m}^{-1}$. All $\mathrm{CVs}$ have been performed using $0.150 \mathrm{M}$ of $\mathrm{KCl}$ electrochemical cell using potassium phosphate buffered solution at $\mathrm{pH} 7.4$, at a scan rate of 10 $\mathrm{mV} \cdot \mathrm{s}^{-1}$. Inset: $\mathrm{C}_{\mathrm{d}}$ of the (A) ITO/electrolyte and (C) ITO-MD/electrolyte at $\pi=33 \mathrm{mN} \cdot \mathrm{m}^{-1}$ system obtained from the CVs.

Fig. 4 presents the $\mathrm{CVs}$ at $10 \mathrm{mV} \cdot \mathrm{s}^{-1}$ of the ITO-MD system transferred at $\pi=33 \mathrm{mN} \cdot \mathrm{m}^{-1}$ (blank) and ITO-MD:PQ system transferred on ITO at several surface pressures. Under the experimental conditions, the CVs start at several positive potentials at which the PQ has the quinone ring in its oxidised form [23]. The potential is first scanned towards cathodic potentials until a final potential, which is determined by hydrogen evolution, and then, the scan is reversed up to the initial potential. The ITO-MD:PQ system at $\pi=33 \mathrm{mN} \cdot \mathrm{m}^{-1}$ shows two reduction and two oxidation peaks, whereas at $\pi=6 \mathrm{mN} \cdot \mathrm{m}^{-1}$ one reduction and two oxidation peaks are observed, and there are no peaks at $\pi=1 \mathrm{mN} \cdot \mathrm{m}^{-1}$. The peaks of process I have been labelled according to the redox behaviour of the system when the voltammogram is cycled in a shorter potential window (inset of Fig. 4) and it is also 
correlated with the process observed for pure PQ at $\pi=2 \mathrm{mN} \cdot \mathrm{m}^{-1}$ (inset of Fig. 4). We assign process II to the second redox process that appears at $\pi \geq 6 \mathrm{mN} \cdot \mathrm{m}^{-1}$ for the ITOMD:PQ system. The two processes I and II remain when scanning at higher scan rates as is shown in Fig. S3 (Supplementary material).

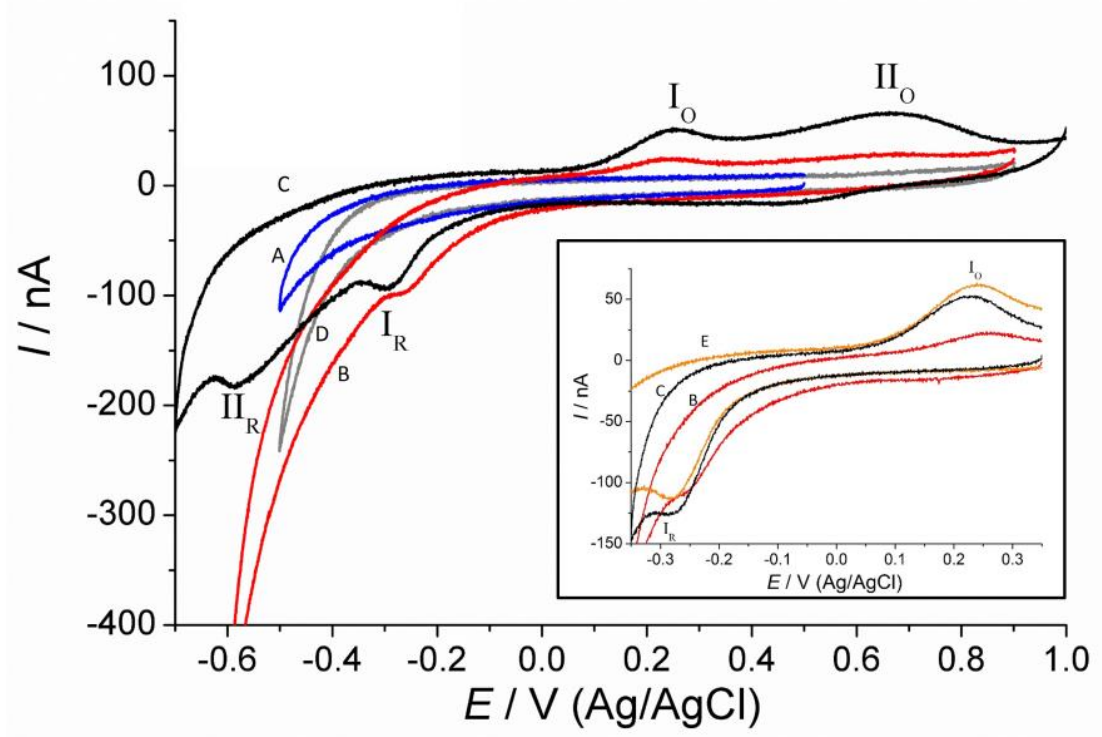

Figure 4. CV of MD:PQ LB films transferred on ITO at several surface pressures: (A) $\pi=1 \mathrm{mN} \cdot \mathrm{m}^{-}$ ${ }^{1}$, (B) $\pi=6 \mathrm{mN} \cdot \mathrm{m}^{-1}$ and (C) $\pi=33 \mathrm{mN} \cdot \mathrm{m}^{-1}$. (D) $\mathrm{CV}$ of the ITO-MD electrode. Inset corresponds to $\mathrm{CV}$ of the ITO-MD:PQ LB film transferred at (B) $\pi=6$ and (C) $33 \mathrm{mN} \cdot \mathrm{m}^{-1}$ and (E) the CV of the ITO-PQ system transferred at $\pi=2 \mathrm{mN} \cdot \mathrm{m}^{-1}$. All CVs have been performed using $0.150 \mathrm{M}$ of $\mathrm{KCl}$ electrochemical cell and a potassium phosphate buffered solution at $\mathrm{pH} 7.4$, at a scan rate of 10 $\mathrm{mV} \cdot \mathrm{s}^{-1}$.

The current intensity of the redox peaks has been studied for the ITO-MD:PQ system at several scan rates, $\mathrm{v}$, (not shown) and it has been found that the reduction and the oxidation current intensity are related by a linear dependence with the scan rate. This observation indicates that PQ molecules are surface confined and that the electron transfer process is not diffusion controlled [24]. This result also indicates that the PQ heads have, in the surface environment, enough $\mathrm{H}^{+}$ions available to accomplish the global reaction (Eq. (6)) at $\mathrm{pH}=7.4[9]$.

$$
\mathrm{PQ}+2 \mathrm{e}^{-}+2 \mathrm{H}^{+} \rightarrow \mathrm{PQH}_{2}
$$

The peak shape of the voltammograms for the ITO-MD:PQ|electrolyte system is not symmetrical, as the reduction peak presents a sharper shape than the oxidation one. A similar situation was observed by Märtensson and Agmo [25] and Hong and Park [26] studying UQ and hydroquinone respectively, and was also observed in our previous work studying the electrochemical behaviour of UQ and PQ on different lipid monolayers on ITO. The different shape of the reduction and oxidation peaks can be explained by the different hydrophilic character of the redox couple $\mathrm{PQ} / \mathrm{PQH}_{2}$. The larger polarity of $\mathrm{PQH}_{2}$ compared with PQ leads the former to establish better attractive interactions by dipoledipole or hydrogen bonding between $\mathrm{PQH}_{2}$ and $\mathrm{MD}$ headgroups and, in addition, the 
$\mathrm{PQH}_{2}$-ITO, $\mathrm{PQH}_{2}-\mathrm{PQH}_{2}$ and $\mathrm{PQH}_{2}$-water interactions are also enhanced $[23,25,27,28]$. These arguments are also valid for explaining the greater width of the oxidation peak compared with that of the reduction process.

The redox peak separation for process II is greater than for process I indicating that process II is even more irreversible than process I. Table 3 shows the formal potentials of processes I and II. Experimentally, the formal potential $E_{f}$ of both processes I and II is calculated as the midpoint between the potentials of the reduction and oxidation peaks, respectively, assuming a quasi-reversible behaviour of the redox system. This could seem a rough approximation but it is a standard procedure for estimating the formal potentials from cyclic voltammetric experiments involving these kinds of complex systems [9-15, 29-32]. The estimation of $E_{f}$ has been made from the values of peak potentials obtained at the low scan rates, to minimise their influence. The values of $\mathrm{E}_{\mathrm{f}}(\mathrm{I})$ for the MD:PQ system are close to the value of $-0.04 \pm 0.03 \mathrm{~V}$ obtained for the ITO-PQ system at $\pi=2 \mathrm{mN} \cdot \mathrm{m}^{-1}$, which indicates that the local environment around each PQ head is similar in these situations. Thus we correlate process I with the redox behaviour of the $\mathrm{PQ} / \mathrm{PQH}_{2}$ molecules placed inside the monolayer with direct contact or a short distance between the ITO surface and the PQ head. On the other hand, while process II is more irreversible than process I, it has a more positive formal potential (close to that of benzoquinone/hydroquinone in aqueous solution $E_{f} \approx 0.08 \mathrm{~V}$ vs. $\mathrm{Ag} / \mathrm{AgCl} / \mathrm{KCl} 3 \mathrm{M}$ at $\mathrm{pH}=7$ ) [24]. This fact can be correlated with the more aqueous environment for the $\mathrm{PQ} / \mathrm{PQH}_{2}$ head groups with higher $\mathrm{H}^{+}$ion availability nearer to the aqueous electrolyte. Therefore, we correlate process II with the redox behaviour of the PQ molecules that have been expelled from the MD matrix and are placed on top of the monolayer.

Table 3. Redox peaks potentials and the formal potential that they represent for the ITO-MD:PQ 5:1 system at $\mathrm{pH}=7.4$.

\begin{tabular}{|ccccccc|}
\hline$\pi\left(\mathrm{mN} \cdot \mathrm{m}^{-1}\right)$ & $E_{p R}(\mathrm{I})(\mathrm{V})$ & $E_{p O}(\mathrm{I})(\mathrm{V})$ & $E_{f}(\mathrm{I})(\mathrm{V})$ & $E_{p R}(\mathrm{II})(\mathrm{V})$ & $E_{p O}(\mathrm{II})(\mathrm{V})$ & $E_{f}(\mathrm{II})(\mathrm{V})$ \\
\hline 6 & $-0.27 \pm 0.03$ & $0.26 \pm 0.02$ & $-0.01 \pm 0.02$ & - & $0.68 \pm 0.02$ & - \\
33 & $-0.29 \pm 0.02$ & $0.23 \pm 0.02$ & $-0.03 \pm 0.02$ & $-0.58 \pm 0.02$ & $0.67 \pm 0.02$ & $0.05 \pm 0.02$ \\
& & & & & & \\
\hline
\end{tabular}

The charge involved in the LB monolayer transferred at each surface pressure is obtained by integrating the area under the reduction or oxidation waves. The surface coverage $(\Gamma)$ is obtained from the experimental values of charge and by considering the global reaction for the $\mathrm{PQ} / \mathrm{PQH} 2$ redox couple (Eq. (6))

The $\Gamma$ for the ITO-MD:PQ/electrolyte system is shown in Table 4 and compared with the expected value to obtain the electroactive fraction of PQ. The expected surface coverage $\left(\Gamma_{\text {expec }}\right)$ values are calculated assuming that the PQ and MD molecules are perfectly spread, accordingly to the corresponding ratio, on the ITO surface, the resulting value being corrected using the transfer ratio associated with it in the LB transfer process. We have chosen to show in Table 4 the oxidation surface coverage $\left(\Gamma_{O}\right)$ of the redox processes, which are similar but lower than the results obtained for the reduction scan that have the undesirable contribution of hydrogen evolution. 
Table 4. Expected and experimental total surface coverage, experimental surface coverage for process I and electroactive fraction involved in the whole redox process for ITO-MD:PQ 5:1/electrolyte system using $0.150 \mathrm{M}$ of $\mathrm{KCl}$ electrochemical cell and potassium phosphate buffered solution at $\mathrm{pH} 7.4$ and at a scan rate of $10 \mathrm{mV} \cdot \mathrm{s}^{-1}$.

\begin{tabular}{|ccccc|}
\hline$\pi$ & $\Gamma_{\text {expec }}$ & $\Gamma_{\mathrm{O} \text { tot }}(\mathrm{I}+\mathrm{II})$ & $\Gamma_{\mathrm{O}}(\mathrm{I})$ & Electroactive \\
$\left(\mathrm{mN} \cdot \mathrm{m}^{-1}\right)$ & $\left(10^{-12} \mathrm{~mol} \cdot \mathrm{cm}^{-2}\right)$ & $\left(10^{-12} \mathrm{~mol} \cdot \mathrm{cm}^{-2}\right)$ & $\left(10^{-12} \mathrm{~mol} \cdot \mathrm{cm}^{-2}\right)$ & fraction $(\%)$ \\
\hline 6 & 35.6 & 8.2 & 8.2 & 23.0 \\
33 & 57.3 & 45.0 & 14.0 & 78.5 \\
\hline
\end{tabular}

The MD:PQ system presents an electrochemical behaviour between that of the MGDG:PQ and the DGDG:PQ systems (Fig. 5). Redox process $\mathrm{I}$ is observed in all systems for monolayers transferred both at low and at high surface pressures. The formal potentials for the MGDG:PQ, DGDG:PQ, MD:PQ and PQ systems are, respectively, $E_{f}(\mathrm{I})=-0.04 \pm 0.03$ $\mathrm{V}, E_{f}(\mathrm{I})=-0.06 \pm 0.03 \mathrm{~V}, E_{f}(\mathrm{I})=-0.03 \pm 0.02 \mathrm{~V}$ and $E_{f}(\mathrm{I})=-0.04 \pm 0.03 \mathrm{~V}$ vs. $\mathrm{Ag} / \mathrm{AgCl} / 3 \mathrm{M} \mathrm{KCl}$ (Table 3 and ref. [9,10]). Redox process I corresponds to PQ molecules placed in the MD matrix and located in direct contact or at a short distance from the electrode surface, which has been labelled diving position. This is the main position of the PQ molecules in the MGDG-PQ system, where only the redox process I takes place (Fig. 5). In the case of the MGDG:PQ system [9] the electrochemical experiments indicated that two different redox peaks $\left(\mathrm{I}_{\alpha}\right.$ and $\left.\mathrm{I}_{\beta}\right)$ are involved in the redox wave that we label as peak $\mathrm{I}$. The two peaks correspond to the PQ in a diving position with PQ head in direct contact with ITO surface $\left(I_{\alpha}\right)$ and PQ in a diving position with no contact $\left(I_{\beta}\right)$, the $I_{\beta}$ peak being favoured at high surface pressures and at high PQ content. The redox process II is observed for the DGDG:PQ and MD:PQ systems and monolayers transferred at medium and high surface pressures, and is the main electrochemical process in the case of DGDG:PQ system. The position of the reduction and oxidation peak potentials give a formal potential of $E_{f}$ (II) $=0.05 \pm 0.03 \mathrm{~V}$ vs. $\mathrm{Ag} / \mathrm{AgCl} / 3 \mathrm{M} \mathrm{KCl}$ for both the DGDG:PQ and MD:PQ systems (Table 3 and ref. [10]). The redox process II corresponds to PQ molecules on the top of the lipid matrix, which has been designated the swimming position.

The proportion of PQ at each position (diving or swimming) is defined by the surface pressure or the physical state of the galactolipid (MGDG, DGDG or MD) monolayer, as is shown in the scheme of Schematic 2 for the MD:PQ system. At low surface pressures, regardless of whether the MD:PQ domains are in LE or LC state (Fig. 2D), the diving position $(\mathrm{I} \alpha)$ predominates. The compression of the monolayer induces the compactness of the LC state favouring the rejection of part of the PQ in diving position. PQ can be vertically rejected both to the diving position without ITO-PQ contact $\left(\mathrm{I}_{\beta}\right)$ and to the swimming position (suggested by the presence of redox process II in the voltammogram), or horizontally rejected to the remaining LE zones, thus enriching them in PQ (also suggested by the fact that the surface coverage values of oxidation peak I increase with the increase of surface pressure). 


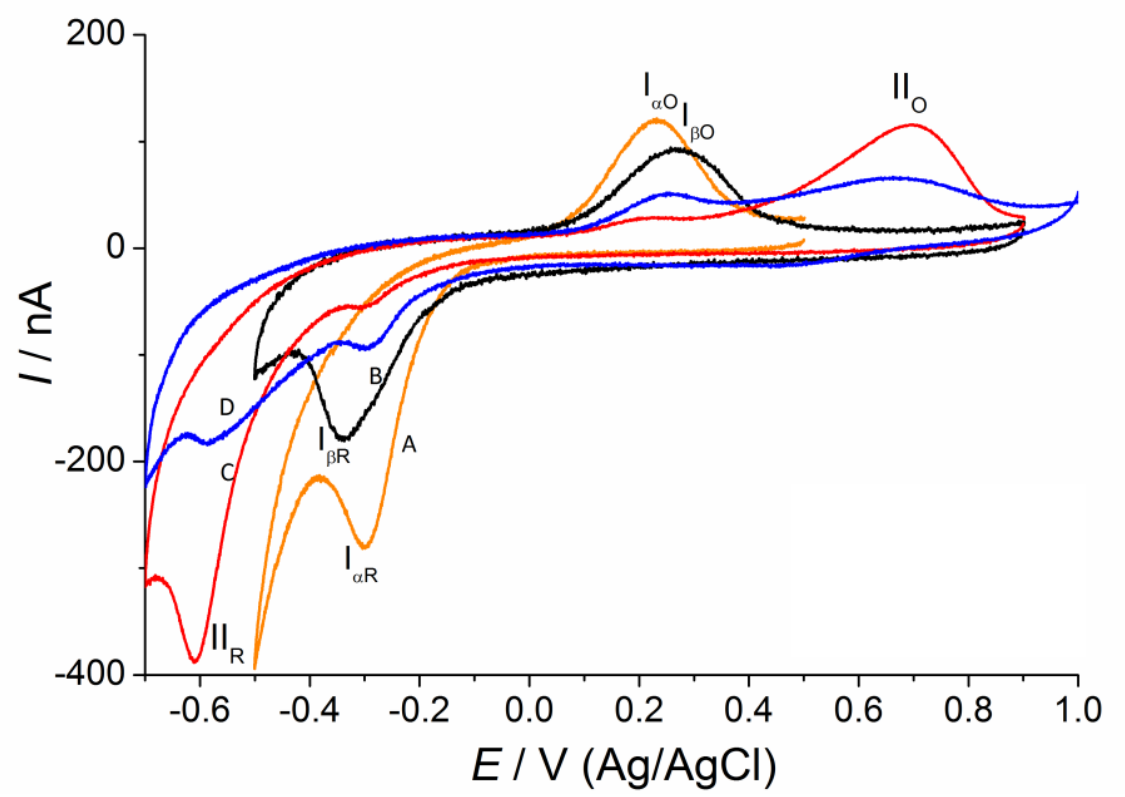

Figure 5. CVs of (A) the ITO-PQ LB film transferred on the collapse and (B, C, D) ITOgalactolipid:PQ LB films ((B) MGDG, (C) DGDG and (D) MD) transferred at $\pi=33 \mathrm{mN} \cdot \mathrm{m}^{-1}$. CVs have been performed using $0.150 \mathrm{M}$ of $\mathrm{KCl}$ electrochemical cell and a potassium phosphate buffered solution at $\mathrm{pH} 7.4$, at a scan rate of $10 \mathrm{mV} \cdot \mathrm{s}^{-1}$.

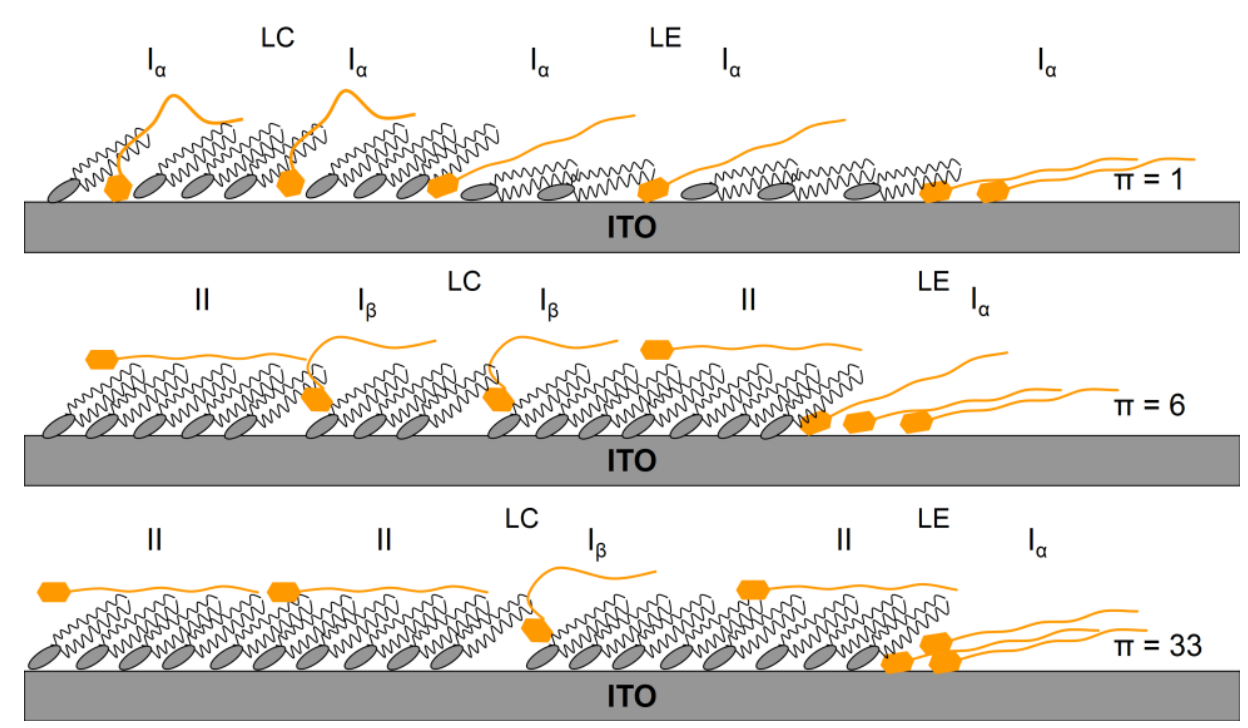

Schematic 2. Scheme of the position of MD and PQ molecules of the MD:PQ system at several surface pressures. The labels $\mathrm{I}_{\alpha}, \mathrm{I}_{\beta}$ and II indicate the PQ positions that origin the redox processes I and II.

All ITO-galactolipid:PQ|electrolyte systems present a higher electroactive fraction with increasing initial PQ content (Table 4 and references $[9,10]$ ), which is explained both by a sufficient presence of available protons close to the PQ heads, which avoids the high local quinone concentration problem, and by the electron hopping effect. The electron transfer takes place mainly by two mechanisms: First, by direct transfer and electron hopping 
between the PQ placed in diving position (process I), and second, by electron hopping through the lipid matrix (process II).

We have estimated the values of the apparent charge transfer rate constant $\left(k_{\mathrm{app}}\right)$ for the electrochemical processes I and II, using Laviron's formalism [33] applied to charge transfer (Eq. (6)). Following this formalism a representation of ( $\left.E_{\text {peak }}-E_{f}\right)$ vs. $\ln (v)$ (not shown) has been performed for the cathodic (Eq. (7)) and anodic (Eq. (8)) peaks of processes I and II at the studied surface pressures, and a good linearity was obtained. The apparent transfer coefficient $\left(\alpha_{\mathrm{app}}\right)$ can be obtained from the slopes $\left(\mathrm{m}_{\mathrm{R}}\right.$ and $\left.\mathrm{mo}_{\mathrm{O}}\right)$ of the linear plots and $\mathrm{k}_{\mathrm{app}}$ from the values of the intercept at the origin. Table 5 presents the $\alpha_{\text {app }}$ and $k_{\text {app }}$ values.

$$
\begin{gathered}
E_{p R}-E_{f}=\frac{R T}{\alpha_{a p p} n F} \ln \left(\frac{R T k_{a p p}}{\alpha_{a p p} n F v}\right)=m_{R} \ln \left(m_{R} k_{a p p}\right)-m_{R} \ln v \\
E_{p O}-E_{f}=-\frac{R T}{\left(1-\alpha_{a p p}\right) n F} \ln \left(\frac{R T k_{a p p}}{\left(1-\alpha_{a p p}\right) n F v}\right)=-m_{O} \ln \left(m_{O} k_{a p p}\right)+m_{O} \ln v
\end{gathered}
$$

Table 5. $\alpha_{\text {app }}$ and $k_{\text {app }}$ values for the ITO-MGDG:PQ, ITO-DGDG:PQ and ITO-MD:PQ systems, estimated from the experimental results at $\pi=33 \mathrm{mN} \cdot \mathrm{m}^{-1}$.

\begin{tabular}{|lccccc|}
\hline & & \multicolumn{2}{c}{ Process I } & \multicolumn{2}{c|}{ Process II } \\
System & & reduction & oxidation & reduction & oxidation \\
& & & & & \\
& $\alpha_{\text {app }}$ & 0.58 & 0.80 & & \\
MGDG:PQ & $\mathrm{k}_{\text {app }} / \mathrm{s}^{-1}$ & $1.1 \times 10^{-6}$ & $8.4 \times 10^{-4}$ & - & 0.86 \\
& $\alpha_{\text {app }}$ & 0.60 & 0.74 & 0.30 & $11.0 \times 10^{-5}$ \\
& $\mathrm{k}_{\text {app }} / \mathrm{s}^{-1}$ & $2.4 \times 10^{-6}$ & $3.2 \times 10^{-4}$ & $54.0 \times 10^{-9}$ & 0.84 \\
& $\alpha_{\text {app }}$ & 0.63 & 0.78 & 0.37 & $5.2 \times 10^{-5}$ \\
& $\mathrm{k}_{\text {app }} / \mathrm{s}^{-1}$ & $0.7 \times 10^{-6}$ & $7.4 \times 10^{-4}$ & $2.2 \times 10^{-9}$ & \\
\hline
\end{tabular}

Table 5 shows, on the one hand, that the $\alpha_{\text {app }}$ and $k_{\text {app }}$ values are different for the reduction, $\mathrm{k}_{\text {Rapp}}$, and oxidation, $\mathrm{k}_{\text {oapp }}$, for both processes I and II. On the other hand, the $\alpha_{\text {app }}$ and $\mathrm{k}_{\text {app }}$ values are similar for the different galactolipid systems. These results indicate that the reduction and oxidation processes of the $\mathrm{PQ} / \mathrm{PQH}_{2}$ redox couple confined to the lipid matrix have a different kinetic control at $\mathrm{pH} 7.4$, as has also been shown for the UQ/ $\mathrm{UQH}_{2}$ redox couple confined in a MGDG lipid monolayer [12]. According to our previous studies [12] and in the conclusions of Marchal et al. [32], in the 6-8 $\mathrm{pH}$ range the rate determining 
step for the oxidation of the $\mathrm{PQ} / \mathrm{PQH}_{2}$ redox couple is the electron transfer process, whereas for the reduction process at $\mathrm{pH}<7.5$ the rate determining step involves the protonation of PQ. Therefore, in our experimental system, we can consider that the apparent constants $\mathrm{k}_{\text {Oapp }}(\mathrm{I})$ and $\mathrm{k}_{\text {Oapp }}$ (II) have the meaning of charge transfer constants whereas the apparent constants $\mathrm{k}_{\text {Rapp }}(\mathrm{I})$ and $\mathrm{k}_{\text {Rapp }}(\mathrm{II})$ include the acid dissociation constant of the intermediate species. The values of $\alpha_{\text {app }}$ for reduction and oxidation process I in the galactolipid-PQ systems are similar to those obtained for the MGDG:UQ system [12], and the $\mathrm{k}_{\text {app }}$ values are of the same order of magnitude. In the case of process II however, the $\alpha_{\text {app }}$ value is significantly lower and the $\mathrm{k}_{\text {app }}$ value is $5 \times 10^{5}$ times higher for the reduction process, whereas for the oxidation process both $\alpha_{\text {app }}$ and $k_{\text {app }}$ values are slightly higher. This could be indicative of a similar local environment for the PQ and UQ heads located in the diving position but a different local environment around the PQ molecules that are reduced via process II. This causes changes in the apparent acid dissociation constant of the intermediate species involved in the reduction pathway.

In natural thylakoid membranes, the PQ molecules are present in two main positions; $\mathrm{PQ}_{\mathrm{A}}$ bounded to the photosynthesis system II (PSII) and $\mathrm{PQ}_{\text {в }}$ that can move freely [6,8]. We have reported [10] that in the case of the DGDG:PQ system the redox potential for the swimming $\mathrm{PQ}$ is $\approx 110 \mathrm{mV}$ more positive than that of the diving PQ. For the MD:PQ system the redox potential for the swimming PQ is $\approx 80 \mathrm{mV}$ more positive than that of the diving $P Q$, which is in close accordance with the fact that the redox potentials of $P_{\mathrm{A}}$ and $\mathrm{PQ}_{\mathrm{B}}$ are separated by $80 \mathrm{mV}[6,34]$. The values of the apparent charge transfer rate constants for process I, kOapp $(\mathrm{I})$, shown in table 5, are similar for the three galactolipid-PQ systems studied. This fact is in concordance with measurements of the fast PSII core complex fluorescence induction that demonstrated that MGDG and DGDG only had minor influence on the reduction kinetics of plastoquinone $\mathrm{Q}_{\mathrm{A}}$ and the artificial PSII electron acceptor 2,5-dimethyl-p-benzoquinone [35]. On the other hand the values of $\mathrm{k}_{\mathrm{Oapp}}(\mathrm{I})$ are of the same order of magnitude that those estimated for the oxidation of plastoquinone pool placed into egg yolk liposomes [36,37].

\section{Conclusions}

In the MD:PQ system, the position of the PQ molecules is controlled by the surface pressure of the MD matrix. At low surface pressures, regardless of whether the MD:PQ domains are in LE or LC state, PQ is located in diving position with PQ placed in the MD matrix in direct contact with the electrode surface. The compression of the monolayer induces two effects: the compacting of the LC state and the phase change from LE to LC of the remaining LE zones. These two actions favour the rejection of part of the PQ in diving position, vertically both to the diving position without ITO-PQ contact and to the swimming position, or horizontally to the remaining LE zones so enriching them in PQ. In the MD matrix, the MGDG leads the phase domains of the lipid matrix and the expulsion of PQ molecules and the DGDG leads its fluidity. The electrochemical behaviour of PQ in the MD matrix is comparable to that of PQ in the MGDG and DGDG matrices with similar values for the peak potentials. The apparent charge transfer rate constants present similar 
values for the MGDG:PQ, DGDG:PQ and MD:PQ systems in concordance with the observed minor influence of MGDG and DGDG on the reduction kinetics on natural $\mathrm{PQ}_{\mathrm{A}}$ molecules. The observations obtained from the galactolipid:PQ systems indicate that the PQ position in the galactolipid matrix can be tuned using the LB technique and controlling the galactolipid composition, the PQ content and the surface pressure. This result is interesting for technological applications since it permits the control of the electron transfer process in biomimetic membranes.

\section{Acknowledgements}

The authors thank the economic support of the Spanish Government, through the project CTQ2007-68101-C02-02 and to the Nanometric Techniques Unit of the ScientificTechnical Services of the University of Barcelona. J Hoyo thanks to Universitat Politècnica de Catalunya (UPC) its PhD grant. The authors also thank Prof. F. Sanz (UB) for the facilities during this research.

\section{References}

[1] H.Gao, G. Luo, J. Feng, A.L. Ottova, H. Ti Tien, Photoelectric conversion properties of bilayer lipid membranes self-assembled on an ITO substrate. J. Electroanal. Chem. 496 (2001) 158-161.

[2] D. Berti, G. Caminatia, P. Baglioni, Functional liposomes and supported lipid bilayers: towards the complexity of biological archetypes. Phys. Chem. Chem. Phys. 13 (2011) 8769-8782.

[3] C. Ge, K.S. Orosz, N.R. Armstrong, S.S. Saavedra, Poly(aniline) nanowires in sol-gel coated ITO: a pH-responsive substrate for planar supported lipid bilayers. ACS Appl Mater Interfaces 7 (2011) 2677-2685.

[4] W. Zhan, K. Jiang, A Modular Photocurrent Generation System Based on Phospholipid Assembled Fullerenes. Langmuir 24 (2008) 13258-13261.

[5] A. Iglic, Advances in Planar Lipid Bilayers and Liposomes, Vol. 13, Elsevier, San Diego, California, 2011.

[6] C. Glöckner, The donor and acceptor side of photosystem II: Structural and functional investigations. Ph.D. thesis, Technischen Universität Berlin, Berlin, 2013.

[7] P. Dörmann, G. Hölzl, in: H. Wada, N. Murata (Eds.), Essential and Regulatory Functions, The Role of Glycolipids in Photosynthesis. Springer, Dordrecht, The Netherlands, 2010, pp. 265-282.

[8] F. Müh, C. Glöckner, J. Hellmich, A. Zouni, Light-induced quinone reduction in photosystem II, Biochim. Biophys. Acta, 1817 (2012) 44-65.

[9] J. Hoyo, E. Guaus, J. Torrent-Burgues, F. Sanz, Biomimetic monolayer films of monogalactosyldiacylglycerol incorporating plastoquinone, J. Phys. Chem. B 119 (2015) 6170-6178.

[10] J. Hoyo, E. Guaus, J. Torrent-Burgues, F. Sanz, Biomimetic monolayer films of digalactosyldiacylglycerol incorporating plastoquinone. Biochim. Biophys. Acta 1848 (2015) 1341-1351. 
[11] J. Hoyo. Electron transfer processes in biomimetic membranes incorporating prenylquinones. Ph.D. thesis, Polytechnic University of Catalonia, Barcelona, 2014.

[12] J. Hoyo, E. Guaus, J. Torrent-Burgues, F. Sanz, Electrochemistry of LB films of mixed MGDG:UQ on ITO. Bioelectrochemistry 104 (2015) 26-34.

[13] J. Hoyo, E. Guaus, J. Torrent-Burgues, Biomimetic monolayer films of monogalactosyldiacylglycerol incorporating ubiquinone. J. Colloid Interface Sci. 384 (2012) 189-197. [14] J. Hoyo, E. Guaus, J. Torrent-Burgues, F. Sanz, Electrochemical behaviour of mixed LB films of ubiquinone - DPPC. J. Electroanal. Chem. 669 (2012) 6-13.

[15] J. Hoyo, E. Guaus, G. Oncins, J. Torrent-Burgués, F. Sanz, Incorporation of Ubiquinone in Supported Lipid Bilayers on ITO. J. Phys. Chem. B 117 (2013) 7498-7506

[16] J. A. Söderhäll, A. Laaksonen, Molecular Dynamics Simulations of Ubiquinone inside a Lipid Bilayer. J. Phys. Chem. B 105 (2001) 9308-9315.

[17] G. Cevc, D. Marsh, Phospholipid Bilayers. Physical Principles and Models. WileyInrscience, New York, 1987.

[18] S. Morandat, K. El Kirat, Cytochrome c provokes the weakening of zwitterionic membranes as measured by force spectroscopy. Colloids Surf. B 82 (2011) 111-117.

[19] P. Vitovič, D.P. Nikolelis, T. Hianik, Study of calix [4] resorcinarene-dopamine complexation in mixed phospholipid monolayers formed at the air|water interface. Biochim. Biophys. Acta 1758 (2006) 1852-1861.

[20] Y. Roche, P. Peretti, S. Bernard, Influence of the chain length of ubiquinones on their interaction with DPPC in mixed monolayers. Biochim. Biophys. Acta 1758 (2006) 468478.

[21] P. Toimil, G. Prieto, J. Jr. Miñones, F. Sarmiento, A comparative study of FDPPC/DPPC mixed monolayers. Influence of subphase temperature on F-DPPC and DPPC monolayers. Phys. Chem. Chem. Phys. 12 (2010) 13323-13332.

[22] H. Yun, Y-W. Choi, N.J. Kim, D. Sohn, Physicochemical Properties of Phosphatidylcholine (PC) Monolayers with Different Alkyl Chains, at the Air/Water Interface. Bull. Korean Chem. Soc. 24 (2003) 377-383.

[23] P.J. Quinn, M.A. Esfahani, Ubiquinones have surface-active properties suited to transport electrons and protons across membranes. Biochem. J. 185 (1980) 715-722.

[24] A.J. Bard, L.R. Faulkner, Electrochemical Methods. Fundamentals and Applications, John Wiley \& Sons, New York, 2001.

[25] C. Mårtensson, V. Agmo Hernández, Ubiquinone-10 in gold-immobilized lipid membrane structures acts as a sensor for acetylcholine and other tetraalkylammonium cations. Bioelectrochemistry 88 (2012) 171-80.

[26] H.G. Hong, W. Park, Electrochemical characteristics of hydroquinone-terminated selfassembled monolayers on gold. Langmuir 17 (2001) 2485-2492.

[27] M. Jemiola-Rzeminska, J. Kruk, M. Skowronek, K. Strzalka, Location of ubiquinone homologues in liposome membranes studied by fluorescence anisotropy of diphenylhexatriene and trimethylammonium-diphenyl-hexatriene, Chem. Phys. of Lipids 79 (1996) 55-63.

[28] R. Bilewicz, S. Sek, I. Zawisza, Electron transport through composite monolayers. Russ. J. Electrochem. 38 (2002) 29-38.

[29] L. Becucci, F. Scaletti, R. Guidelli, Gel-phase microdomains and lipid rafts in monolayers affect the redox properties of ubiquinone-10, Biophys. J. 101 (2011) 134-143.

[30] D. Marchal, W. Boireau, J. M. Laval, J. Moiroux, C. Bourdillon, Electrochemical measurement of lateral diffusion coefficients of ubiquinones and plastoquinones of various isoprenoid chain lengths incorporated in model bilayers, Biophys. J. 74 (1998) 1937-1948 
[31] G. J. Gordillo, D. J. Schiffrin, Redox properties of ubiquinon (UQ10) adsorbed on a mercury electrode, J. Chem. Soc. Faraday Trans. 90 (1994) 1913-1922.

[32] D. Marchal, W. Boireau, J.M. Laval, C. Bourdillon, J. Moiroux, Kinetics of redox conversion at a gold electrode of water-insoluble ubiquinone (UQ(10)) and plastoquinone (PQ(9)) incorporated in supported phospholipid layers, J. Electroanal. Chem. 451 (1998) 139-144.

[33] E. Laviron, E. General expression of the linear potential sweep voltammogram in the case of diffusionless electrochemical systems. J. Electroanal. Chem. 101 (1979) 19-28.

[34] D. J. Vinyard, G. M. Ananyev, G. C. Dismukes, The Reaction Center of Oxygenic Photosynthesis, Annu. Rev. Biochem. 82 (2013) 577-606.

[35] M. Kany, C. Wilhelm, R. Gross, Influence of thylakpoid membrane lipids on the structure and function of the plant photosystem II complex, Planta 240 (2014) 781-796.

[36] B. Ivanov, M. Mubarakshina, S. Khorobrykh, Kinetics of the plastoquinone pool oxidation following illumination Oxygen incorporation into photosynthetic electron transport chain, FEBS Letters 581 (2007) 1342-1346.

[37] J Kruk, M. Jemioła-Rzeminska, K, Strzałka, Plastoquinol and $\alpha$-tocopherol quinol are more active than ubiquinol and $\alpha$-tocopherol in inhibition of lipid peroxidation, Chemistry and Physics of Lipids 87 (1997) 73-80. 


\section{Supplementary material}

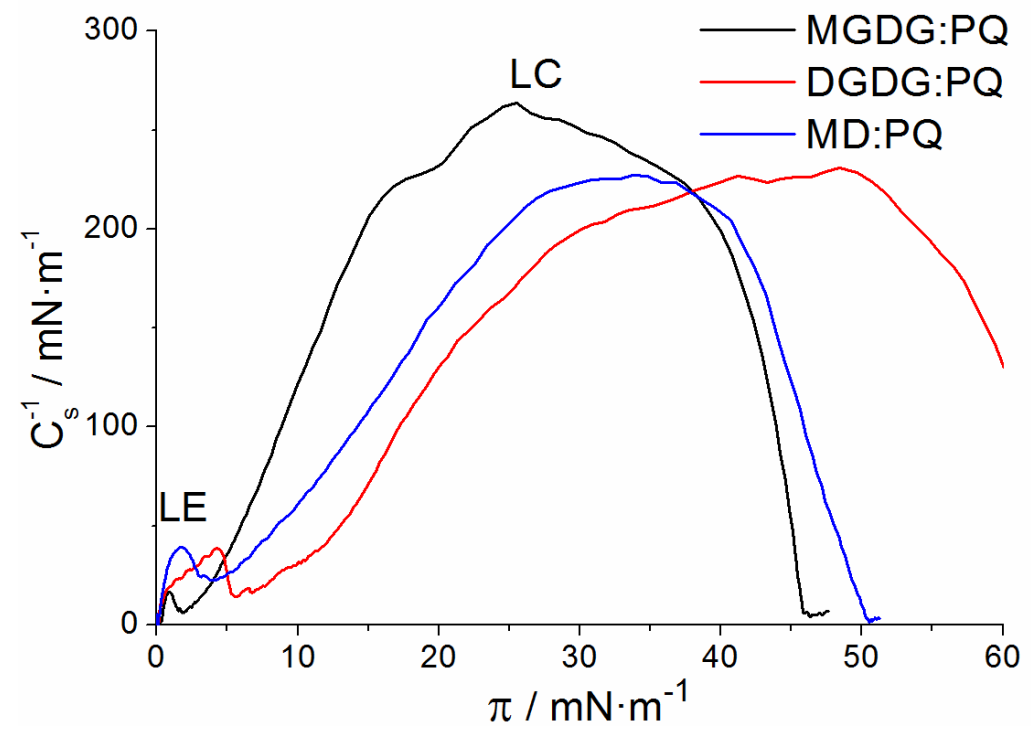

Figure S1. Inverse of the compressibility modulus for MGDG:PQ, DGDG:PQ and MD:PQ mixtures at $21 \pm 1^{\circ} \mathrm{C}$ on water subphase.
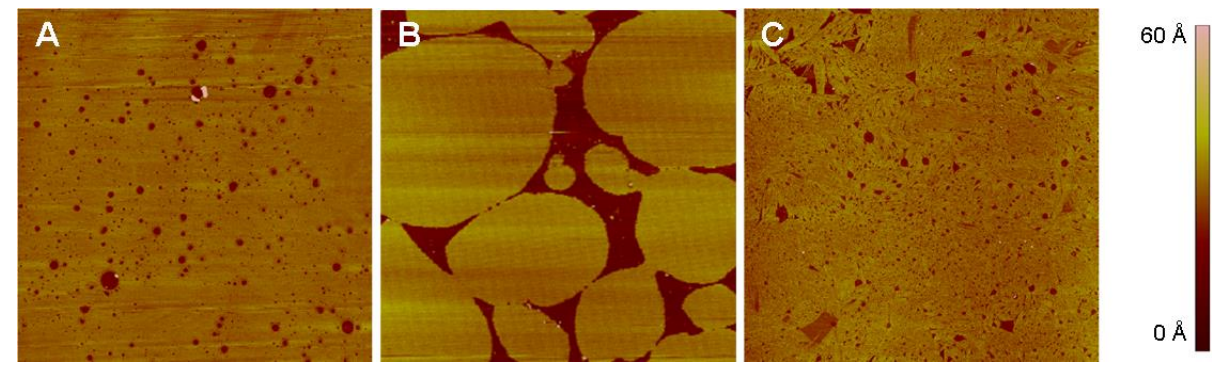

Figure S2. AFM topographic images $(10 \mu \mathrm{m} \times 10 \mu \mathrm{m})$ at $15 \mathrm{mN} \cdot \mathrm{m}^{-1}$ for A) MGDG:PQ, B) DGDG:PQ, C) MD:PQ. 


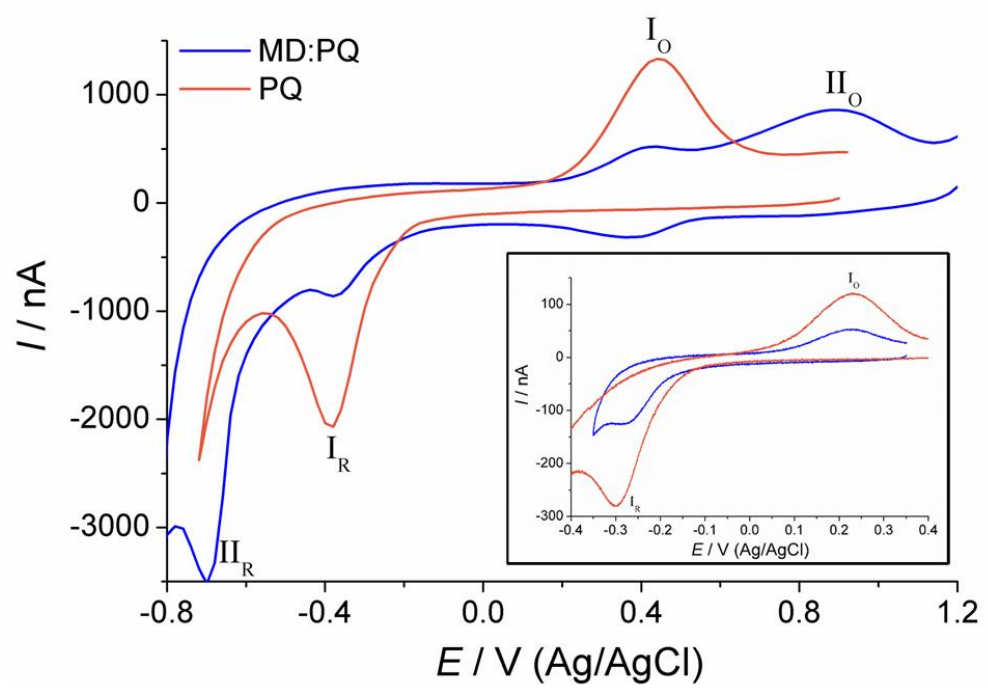

Figure S3. CVs of ITO-MD:PQ|electrolyte LB film transferred at $\pi=33 \mathrm{mN} \cdot \mathrm{m}^{-1}$ and ITOPQ system transferred at $\pi=2 \mathrm{mN} \cdot \mathrm{m}^{-1}$, both scanned at $200 \mathrm{mV} \cdot \mathrm{s}^{-1}$. All CVs have been performed using $0.150 \mathrm{M}$ of $\mathrm{KCl}$ electrochemical cell and potassium phosphate buffered solution at $\mathrm{pH} 7.4$.

Table S1. Physical states of each zone (dark and light brown) at $\pi=15 \mathrm{mN} \cdot \mathrm{m}^{-1}$ and height ( $)$ of all the physical states observed for the LB monolayers corresponding to the studied galactolipid:PQ mixtures.

\begin{tabular}{|lccccc|}
\hline & Dark & Light & LE & LC1 & LC2 \\
MGDG:PQ & LE & LC2 & $6 \pm 2$ & $24 \pm 1$ & $26 \pm 1$ \\
DGDG:PQ & LE & LC1 & $6 \pm 2$ & $21 \pm 1$ & $23 \pm 1$ \\
MD:PQ & LE & LC1 & $6 \pm 2$ & $22 \pm 1$ & $24 \pm 1$ \\
\hline
\end{tabular}

